\title{
Estimation of Water Diffusion Coefficient into Polycarbonate at Different Temperatures Using Numerical Simulation
}

Shojaee Nasirabadi, Parizad; Jabbaribehnam, Mirmasoud; Hattel, Jesper Henri

Published in:

A I P Conference Proceedings Series

Link to article, DOI:

$10.1063 / 1.4951801$

Publication date:

2016

Document Version

Publisher's PDF, also known as Version of record

Link back to DTU Orbit

Citation (APA):

Shojaee Nasirabadi, P., Jabbaribehnam, M., \& Hattel, J. H. (2016). Estimation of Water Diffusion Coefficient into Polycarbonate at Different Temperatures Using Numerical Simulation. A I P Conference Proceedings Series, 1738, [030045]. https://doi.org/10.1063/1.4951801

\section{General rights}

Copyright and moral rights for the publications made accessible in the public portal are retained by the authors and/or other copyright owners and it is a condition of accessing publications that users recognise and abide by the legal requirements associated with these rights.

- Users may download and print one copy of any publication from the public portal for the purpose of private study or research.

- You may not further distribute the material or use it for any profit-making activity or commercial gain

- You may freely distribute the URL identifying the publication in the public portal 


\title{
Estimation of Water Diffusion Coefficient into Polycarbonate at Different Temperatures Using Numerical Simulation
}

\author{
P. Shojaee Nasirabadi, M. Jabbari and J.H. Hattel \\ Process Modelling Group, Department of Mechanical Engineering, Technical University of Denmark, Nils \\ Koppels Allé, 2800 Kgs. Lyngby, Denmark.
}

\begin{abstract}
Nowadays, many electronic systems are exposed to harsh conditions of relative humidity and temperature. Mass transport properties of electronic packaging materials are needed in order to investigate the influence of moisture and temperature on reliability of electronic devices. Polycarbonate (PC) is widely used in the electronics industry. Thus, in this work the water diffusion coefficient into PC is investigated. Furthermore, numerical methods used for estimation of the diffusion coefficient and their assumptions are discussed. 1D and 3D numerical solutions are compared and based on this, it is shown how the estimated value can be different depending on the choice of dimensionality in the model.
\end{abstract}

Keywords: adsorption, polycarbonate, diffusion coefficient, water

PACS: $80 \mathrm{~A} 20$

\section{INTRODUCTION}

More and more electronics are being used in climatically harsh environments. Therefore, the challenge of climateprotective packaging increases [1]. High humidity and condensation are responsible for several harmful effects on electronic devices such as corrosion and short circuit failures which can seriously influence reliability and life time of these devices. Despite the increased climatic load, as of today, long lifetime and high reliability of electronic devices is expected [2].

In the electronics industry, polymeric packaging materials are widely used in integrated circuit packages and plasticencapsulated microcircuits to protect them against environmental effects. The hygroscopic and thermal stresses in polymeric packaging induced by hot and humid conditions are important issues as they affect component reliability. In the absence of heat, the direct effect of absorbed moisture in polymeric materials due to humidity includes plasticization hydrolysis, swelling of the material, and reduction of the glass transition temperature as well as storage modulus. In the presence of heat, these deleterious effects are exacerbated as heat accelerates the movement of moisture [3]. Thus, water vapor sorption and permeation characteristics of polymers are important for packaging.

Polycarbonate (PC) is an amorphous engineering thermoplastic, widely used in electronics industry. PC has excellent clarity, toughness, and a high softening temperature [4]. It is known that humid environments can significantly alter the mechanical properties of PC including impact strength, fracture strain, and also thermo-physical properties such as glass transition temperature and viscosity [3]. Therefore, it is important to investigate mass transport properties of PC. In this work, diffusion coefficient values and their estimation method, reported in different studies in literature are discussed. Then, numerical simulations used for estimation of the diffusion coefficients are investigated. Furthermore, water sorption into PC is numerically modelled in 3D because obviously, a 3D investigation is closer to reality compared to a 1D one. However, choosing proper dimensions for the piece of PC as well as a proper configuration for the experiments, the transport phenomenon can reasonably be considered 1D. Then, the results are compared with literature experimental data and it is shown how the choice of dimensionality can influence the estimated values.

\section{THEORY AND METHOD}

Different values for water diffusion coefficient into PC have been reported in different studies. Table.1 is an overview of these values. It is seen that these values range from $0.51 \times 10^{-11}$ to $10 \times 10^{-11} \mathrm{~m}^{2} / \mathrm{s}$ for a wide range of temperature. As expected, the diffusion coefficient increases with temperature in each study. The relation between the diffusion coefficient and temperature $(\mathrm{T}(\mathrm{K}))$ can be described by an Arrhenius equation [5]. 


$$
D=D_{0} \exp \left(-E_{D} / R T\right)
$$

where $\mathrm{R}(8.315 \mathrm{~J} /(\mathrm{mol} \cdot \mathrm{K}))$ is the universal gas constant, and $E_{D}(\mathrm{~J} / \mathrm{mol})$ is the activation energy. If the diffusion coefficients at two different temperatures are known, $E_{D}$ and $D_{0}$ can be determined. Therefore, the diffusion coefficient at any arbitrary temperature can be calculated [6]. However, more data points can increase the accuracy. Moon et al. [4] calculated $E_{D}$ and $D_{0}$ using four data points with an R-squared of 0.9969 ; which showed good resemblance for the Arrhenius equation.

Not surprisingly, the investigated PC in each of these studies had been provided from different sources. This can be one of the reasons for the differences in the reported values. Another reason can be the estimation method used in each of these studies.

TABLE 1. An overview of water diffusion coefficient into PC reported in different studies.

\begin{tabular}{lccccc}
\hline$D\left(\mathrm{~m}^{2} / \mathrm{s}\right)$ & Temperature $\left({ }^{\circ} \mathrm{C}\right)$ & Ref. & $D\left(\mathrm{~m}^{2} / \mathrm{s}\right)$ & Temperature $\left({ }^{\circ} \mathrm{C}\right)$ & Ref. \\
$0.65 \times 10^{-11}$ & 23 & {$[7]$} & $5.34 \times 10^{-11}$ & 80 & {$[4]$} \\
$0.51 \times 10^{-11}$ & 25 & {$[4]$} & $6 \times 10^{-11}$ & 80 & {$[8]$} \\
$1.13 \times 10^{-11}$ & 40 & {$[4]$} & $1.03 \times 10^{-11}$ & 90 & {$[6]$} \\
$2.62 \times 10^{-11}$ & 60 & {$[4]$} & $10 \times 10^{-11}$ & 96 & {$[7]$} \\
$0.53 \times 10^{-11}$ & 75 & {$[6]$} & $8.7 \times 10^{-11}$ & 100 & {$[8]$} \\
\hline
\end{tabular}

In these studies, analytical solution of 1D form of Fick's second law was used to estimate the diffusion coefficient. Furthermore, in all these works, it is assumed that the diffusion coefficient is not concentration dependent $[4,6,7,8]$.

In this study, 3D form of Fick's second law (Equation 2) is solved for a PC plate. All the six faces of the plate are assumed to be in equilibrium with the ambient RH and initial moisture content of it is considered to be zero.

$$
\frac{\partial \mathbf{c}}{\partial t}=D\left(\frac{\partial^{2} c}{\partial^{2} x}+\frac{\partial^{2} c}{\partial^{2} y}+\frac{\partial^{2} c}{\partial^{2} z}\right)
$$

\section{RESULTS AND DISCUSSION}

Considering 1D diffusion into a solid plate, mass transfer is only considered in one direction (thickness); however a 3D approach also considers the two other dimensions. In fact, in the 3D approach all six faces of the plate are considered to be in contact and equilibrium with the ambient $\mathrm{RH}$; however, in the 1D, only the two big faces are taken into account. Thus, the transfer rate is bigger in case of 3D compare to $1 \mathrm{D}$ and consequently, the 3D approach estimates a lower value for diffusion coefficient. Figure. 1 (a) compares 1D and 3D numerical solution of Fick's second law for a PC plate studied by Golovoy et al. [8]. Figure. 1 (b) shows how one can make better estimation of the diffusion time using a thinner PC plate. Generally, it seems more reasonable if the width and length of the studied plate are the same; so that their ratio to the thickness are the same.

As expected, when the PC thickness gets smaller relative to the two other dimensions, the diffusion times which the 1D and 3D approaches predict, get closer (see Figure .1). Figure .1 demonstrates the importance of the dimensions of the investigated piece of PC. In fact, in order to have a reasonable estimation using simplified 1D analytical equations, it is essential to make sure that the thickness of the investigated PC is small enough compared to the width and length. Using the 1D solution, the diffusion coefficient was estimated to $6 \times 10^{-11}$ and $8.7 \times 10^{-11}\left(\mathrm{~m}^{2} / \mathrm{s}\right)$ at 80 and $100^{\circ} \mathrm{C}$, respectively [8]. The current 3D solution estimates lower values $\left(2.5 \times 10^{-11}\right.$ and $4.5 \times 10^{-11}\left(\mathrm{~m}^{2} / \mathrm{s}\right)$, respectively). Figure .2 compares experimental data from Golovoy et al.[8] s' work with 3D simulation results at 80 and $100{ }^{\circ} \mathrm{C}$.

The diffusion coefficients estimated by the present 3D solution show very good agreement with experimental data, according to Figure . 2. The behavior of PC being in contact with RHs of 56, 73, 87 and $95 \%$ at $100^{\circ} \mathrm{C}$ is also simulated using the new estimated diffusion coefficients. Figure .3 compares these simulation results with experimental data from Golovoy et al.[8] s' work. The agreement between the simulation results and the experimental data (see Figure .3) shows that a 3D estimation of the diffusion coefficient leads to more accurate results.

The water concentration in PC (c), in equilibrium with a certain amount of RH can be calculated by Equation (3).

$$
c=s \times R H(\%)
$$



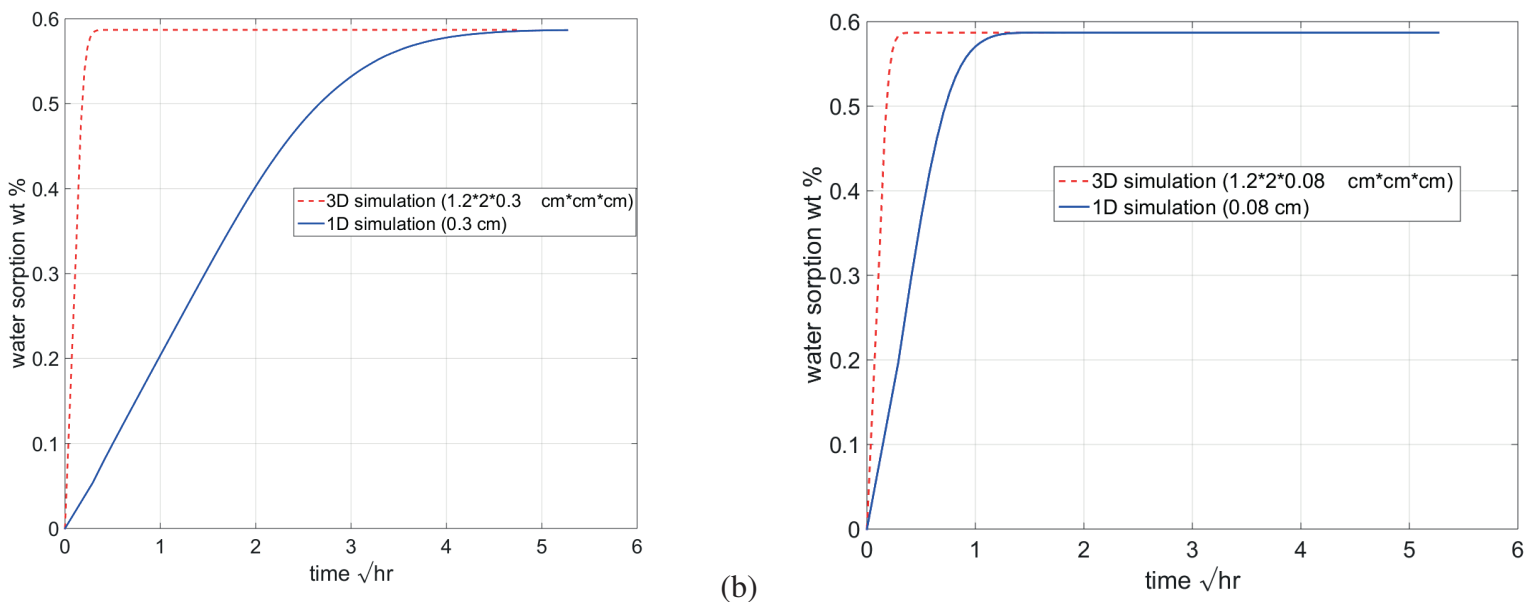

(a)

FIGURE 1. Comparison between 1D and 3D numerical solution of Fick's second law for two sizes of PC pieces

(a)

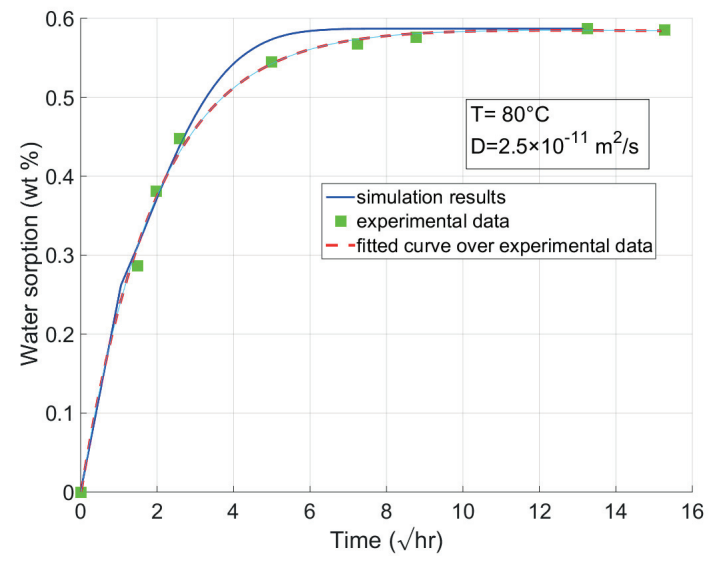

(b)

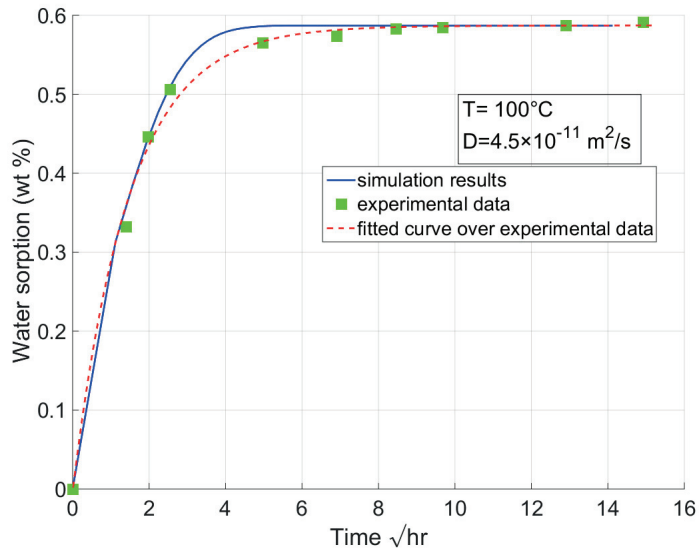

FIGURE 2. Comparison between 3D simulation and experimental data from Golovoy et al. [8] s' work

where $s$ is water solubility in PC. Table.2 compares the predicted c with experimental values reported by Golovoy et al [8]. Equation .2 shows only some minor error, (see Table .2). Thus, using these calculations seems reasonable for estimating adsorption isotherms.

TABLE 2. Comparison between predicted $c$ and experimental data from Golovoy et al [8].

\begin{tabular}{lccc}
$R H(\%)$ & Equilibrium $c(w t \%)[8]$ & Predicted equilibrium $c((w t(\%))$ [this work] & Difference percentage $(\%)$ \\
56 & 0.3211 & 0.3327 & -0.580 \\
73 & 0.4276 & 0.4337 & -0.305 \\
87 & 0.5108 & 0.5169 & -0.305 \\
95 & 0.5722 & 0.5644 & 0.390 \\
\hline
\end{tabular}

\section{CONCLUSIONS}

In this study, reported values from the literature for the water diffusion coefficient into PC were investigated. It was shown that it is very important to choose proper dimensions of the PC in order to estimate the diffusion coefficient. 


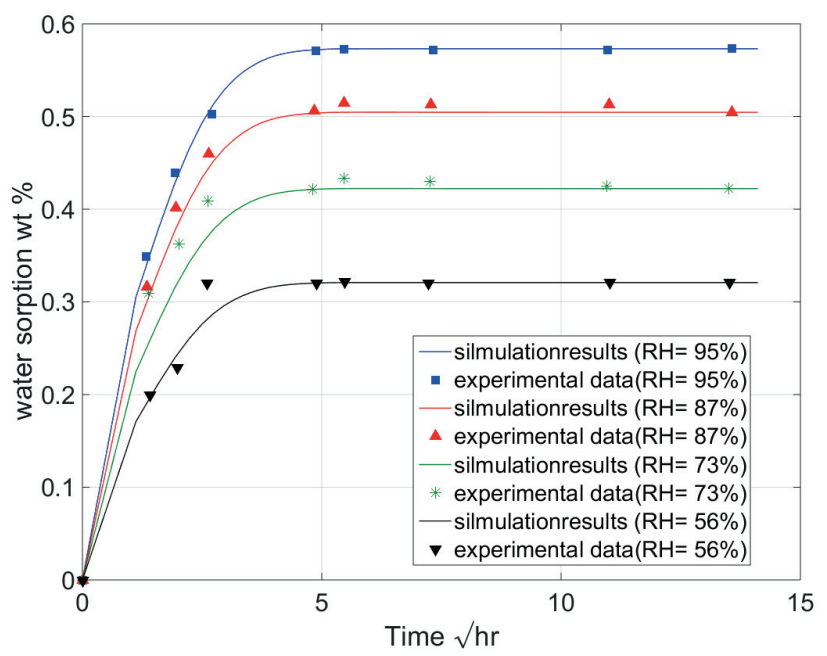

FIGURE 3. Behavior of $\mathrm{PC}$ exposed to different RHs at $100^{\circ} \mathrm{C}$.

Most of the studies have used simplified equations based on 1D solution of Fick's second law. The 3D form of Fick's second law could successfully predict water sorption into PC and the simulation results were in good agreement with experimental data. Water solubility into PC values at different RHs can be used to predict isotherms.

\section{ACKNOWLEDGMENTS}

The current research has been conducted as part of the ICCI project from the Danish council for Independent Research, Technology and Production (FTP) and the IN SPE project from the Danish Innovations Fonden which are highly acknowledged. Moreover, the authors would like to acknowledge the commitment and help of the industrial partners in this project.

\section{REFERENCES}

1. J. B. Jacobsen, J. P. Krog, A. H. Holm, L. Rimestad, and A. Riis, IEEE Ind. Electron. Mag. 8, 51-59 (2014).

2. J. B. Jacobsen, J. P. Krog, L. Rimestad, A. Riis, and A. H. Holm, "Climatic challenges and product level solutions for electronics in demanding applications," in IMAPS Nordic, 2012.

3. M. Haghighi-Yazdi, and .Lee-Sullivan, Acta Mech. 225, 929-950 (2014).

4. S. I. Moon, and C. W. Extrand, Ind. Eng. Chem. Res. 48, 8961-8965 (2009).

5. Food Structure and Moisture Transfer, Springer, 2013.

6. Z. Mao, X. Luo, J. Yang, and S. Liu, "Moisture Diffusivity Analysis of Polycarbonate for LED Lens," in 2010 11th International Conference on Electronic Packaging Technology, 2010.

7. L. M. Robeson, and S. Crisafulli, J. Appl. Polym. Sci. 28, 2925-2936 (1983).

8. A. Golovoy, and M. Zinbo, Polym. Eng. Sci. 29, 1733-1737 (1989). 